\title{
Immunolocalization of dually phosphorylated MAPKs in dividing root meristem cells of Vicia faba, Pisum sativum, Lupinus luteus and Lycopersicon esculentum
}

\author{
Konrad Winnicki $\cdot$ Aneta Żabka $\cdot$ Joanna Bernasińska • \\ Karolina Matczak · Janusz Maszewski
}

Received: 8 October 2014/Revised: 13 January 2015/ Accepted: 19 January 2015/Published online: 5 February 2015

(C) The Author(s) 2015. This article is published with open access at Springerlink.com

\begin{abstract}
Key message In plants, phosphorylated MAPKs display constitutive nuclear localization; however, not all studied plant species show co-localization of activated MAPKs to mitotic microtubules.

Abstract The mitogen-activated protein kinase (MAPK) signaling pathway is involved not only in the cellular response to biotic and abiotic stress but also in the regulation of cell cycle and plant development. The role of MAPKs in the formation of a mitotic spindle has been widely studied and the MAPK signaling pathway was found to be indispensable for the unperturbed course of cell division. Here we show cellular localization of activated MAPKs (dually phosphorylated at their TXY motifs) in both interphase and mitotic root meristem cells of Lupinus luteus, Pisum sativum, Vicia faba (Fabaceae) and
\end{abstract}

Communicated by k. K. Kamo.

Electronic supplementary material The online version of this article (doi:10.1007/s00299-015-1752-6) contains supplementary material, which is available to authorized users.

K. Winnicki $(\bowtie) \cdot$ A. Żabka · J. Maszewski

Department of Cytophysiology, Faculty of Biology and

Environmental Protection, University of Lodz,

ul. Pomorska 141/143, 90-236 Lodz, Poland

e-mail: winnicki@biol.uni.lodz.pl

J. Bernasińska

Department of Molecular Biophysics, Faculty of Biology and

Environmental Protection, University of Lodz,

ul. Pomorska 141/143, 90-236 Lodz, Poland

K. Matczak

Department of Thermobiology, Faculty of Biology and

Environmental Protection, University of Lodz,

ul. Pomorska 141/143, 90-236 Lodz, Poland
Lycopersicon esculentum (Solanaceae). Nuclear localization of activated MAPKs has been found in all species. Colocalization of these kinases to mitotic microtubules was most evident in L. esculentum, while only about $50 \%$ of mitotic cells in the root meristems of $P$. sativum and $V$. faba displayed activated MAPKs localized to microtubules during mitosis. Unexpectedly, no evident immunofluorescence signals at spindle microtubules and phragmoplast were noted in L. luteus. Considering immunocytochemical analyses and studies on the impact of FR180204 (an inhibitor of animal ERK1/2) on mitotic cells, we hypothesize that MAPKs may not play prominent role in the regulation of microtubule dynamics in all plant species.

Keywords Mitogen-activated protein kinase (MAPK) . Mitotic spindle · TEY motif · Phosphorylation cascade · Signaling

\section{Introduction}

The mitogen-activated protein kinase (MAPK) signaling pathway is comprised of three levels of sequentially activated modules, including mitogen-activated protein kinase kinase kinases (MAPKKKs), mitogen-activated protein kinase kinases (MAPKKs) and a group of effector serine/threonine kinases termed mitogen-activated protein kinases (MAPKs) at the bottom of a cascade (Taj et al. 2010). In mammals, 14 different MAPKs were found and classified into two separate subtypes: conventional and non-conventional. The former include ERK1/2 (extracellular signal-regulated kinase 1/2), p38, JNK/ SAPK (stress-activated protein kinase) and ERK5 (Mishra et al. 2006; Cargnello and Roux 2011). Genome-wide analysis identified 16 members of MAPKs in a tomato. Transcripts of most analyzed genes were found in petal, stem, flower and 
fruit. However, expression of the majority of MAPKs was higher in reproductive organs than in vegetative ones (Kong et al. 2012). Up to 20 MAPKs have been identified in the genome of Arabidopsis thaliana so far (MAPK group 2002). Studies concerning MAPK signaling pathway are not limited to plants with sequenced genomes. Ortiz-Masia et al. (2008) investigated the function of MPK2 in Pisum sativum and found it expressed in vegetative and reproductive organs. Interestingly, roots exhibited the highest level of expression.

MAPKs are activated by dual phosphorylation of threonine and tyrosine in their conservative TXY motif ( $\mathrm{X}$ is any amino acid). An activation loop of plant MAPKs may contain either a TEY (Thr-Glu-Tyr) sequence (kinases related to animal ERK) or a TDY (Thr-Asn-Tyr) sequence (distinctive of plants). Plant genomes studied so far have revealed no TPY (Thr-Pro-Tyr) or TGY (Thr-Gly-Tyr) sequences present in animal JNK and p38 kinase, respectively (Ulm 2003; Mishra et al. 2006). Interestingly, novel TQY (Thr-Gln-Tyr) phosphorylation motif of MAPKs described previously in nematodes was also found in legumes (Neupane et al. 2013a, b).

MAPK signaling pathway is a multifunctional cascade implicated in many cellular processes. MAPKs were found activated in response to biotic and abiotic stress, such as cold, salt, drought, wounding, chemical DNA damaging agents, UV and ionizing radiation (Ligterink et al. 1997; Tena et al. 2001; Ulm et al. 2001; Ulm 2003; Nakagami et al. 2005; Mishra et al. 2006; Pitzschke and Hirt 2006; Taj et al. 2010; Sinha et al. 2011). In all cases, activated MAPKs regulate gene expression via transcription factors. Thus, in animals, the main paradigm assumes inducible nuclear localization of MAPKs. On the other hand, in plants there is an ongoing controversy whether nuclear localization of these kinases is inducible or not. Depending on a plant model, some studies point to a constitutive nuclear localization of plant MAPKs, while others indicate an inducible recruitment to the nucleus (Šamajová et al. 2013).

Apart from environmental stress, MAPK signaling cascade is implicated in cell growth, cell cycle regulation, cell differentiation and development. Different types of MAPKs regulate cytoskeleton rearrangements (microtubules and actin filaments). Interestingly, MPK6, one of A. thaliana MAPKs, was also found to localize to the plasma membrane and secretory trans-Golgi network vesicles (Wrzaczek and Hirt 2001; Müller et al. 2010; Šamajová et al. 2013). Furthermore, Fernandez-Pascual et al. (2006) showed contribution of MAPKs to the symbiosis of Bradyrhizobium and Lupinus albus. The involvement of MAPK signaling pathway in other processes is still to be found.

At present, MAPKs are intensively studied for their interactions with microtubules. The mitotic spindle stability requires the activity of MAPKs in Xenopus egg extracts (Horne and Guadagno 2003). In Arabidopsis, MPK4 and MPK6 were found to localize to the phragmoplast during cytokinesis, ensuring an unperturbed cell division (Beck et al. 2011; Komis et al. 2011; Šamajová et al. 2013). Investigations in animals (Horne and Guadagno 2003) and plants (Krysan et al. 2002; Beck et al. 2011) indicate an essential role of MAPK signaling during mitosis. Proper microtubule dynamics require phosphorylation of MAP65 proteins (a group of microtubule associated proteins). This posttranslational modification diminishes the ability of MAP65 to bind microtubules and thus reduces microtubule bundling (Sasabe et al. 2006; Smertenko et al. 2006; Kosetsu et al. 2010). For example, MAP65 inactivation is indispensable during expansion of a phragmoplast and a defect in MPK4 results in microtubule bundling. Studies concerning MAPK signaling pathway mutants (anp2, anp3 and $m p k 4$ ) in plants show failures in both mitotic spindle formation and cytokinesis which lead to the formation of bi- and multinucleate cells (Beck et al. 2011).

Most studies on MAPK signaling pathway in plants were performed on model organisms, such as A. thaliana, Nicotiana tabacum and Medicago sativa. The role of plant MAPKs was investigated mainly in mutants and their localization (irrespective of their activity) was mostly determined by GFP-tagging or immunodetection of whole molecules. The abundance of MAPKs identified in A. thaliana and numerous processes they are involved in, raise the question of whether the range of cellular functions controlled by these kinases is invariable among plant species or if there are differences developed in the course of evolution.

Here, we show localization of activated MAPKs in plants representing two distinct families, i.e. Fabaceae (Lupinus albus, P. sativum and Vicia faba) and Solanaceae (Lycopersicon esculentum). To study this, commercially available antibodies against dually phosphorylated TEY sequence in animal p44/42 kinases were applied. However, due to potential cross-reactivity of these antibodies, it is possible to immunodetect both types of MAPKs, with TEY and TDY motifs. To the best of our knowledge, this is the first presentation of cellular localization of dually phosphorylated MAPKs in plants. Observations performed on selected species confirm the previously postulated role of activated MAPKs in the function of a mitotic spindle. However, a small number or lack of immunopositive mitotic cells in some species and differential response to FR180204, an inhibitor of animal ERK1/2 kinases (Ohori et al. 2007; Qian et al. 2008; Perrett et al. 2013), may suggest that not all plants engage MAPK signaling pathway to regulate microtubule dynamics during cell division.

\section{Materials and methods}

Material

Seeds of Lycopersicon esculentum var. Faworyt, Vicia faba subsp. minor var. Nadwiślański, P. sativum L., Lupinus 
luteus var. Mister and Arabidopsis thaliana were sown on wet filter paper in Petridishes and germinated for 3 days at $25{ }^{\circ} \mathrm{C}$ in darkness. For experiments, selected seedlings (with equally sized roots) were placed in Petridishes with water (control), with $80 \mu \mathrm{M}$ FR180204 (Sigma) for 6 and $24 \mathrm{~h}$ or with $0.01 \%$ (v/v) methyl methanesulfonate (MMS, Sigma) for $6 \mathrm{~h}$.

\section{Western blotting}

Proteins were extracted from root apical fragments $(3 \mathrm{~mm})$ with the use of P-PER Plant Protein Extraction Kit (Thermo Scientific) supplemented with Halt $^{\mathrm{TM}}$ protease and phosphatase inhibitor cocktail (Thermo Scientific). The extracts were fractionated on NuPAGE ${ }^{\circledR}$ Novex $^{\circledR} 4-12 \%$ Bis-Tris gel (Invitrogen) and then blotted onto polyvinylidene fluoride (PVDF) membrane, 0.2- $\mu \mathrm{m}$ pore size (Invitrogen). A blocking buffer was prepared according to the vendor's instructions (Chromogenic Western Blot Immunodetection Kit, Invitrogen). Dually phosphorylated TEY-type MAPKs were detected using monoclonal antiphospho-p44/44 MAPK antibodies diluted 1:1,000 (Cell Signaling) and secondary goat anti-rabbit IgG antibody conjugated with alkaline phosphatase. The chromogenic reaction was run for $15 \mathrm{~min}$. For total protein detection, PVDF membranes were stained with Ponceau $S$ stain (Sigma) for $15 \mathrm{~min}$.

Co-localization of dually phosphorylated MPAKs and microtubules

Root apical fragments $(3 \mathrm{~mm})$ were fixed in $4 \%(\mathrm{w} / \mathrm{v})$ paraformaldehyde buffered with MTSB (50 mM PIPES, $5 \mathrm{mM}$ EGTA, $5 \mathrm{mM} \mathrm{MgSO}$, $\mathrm{pH}$ 7.0) for $45 \mathrm{~min}$, and then rinsed twice in PBS and transferred for $20 \mathrm{~min}$ (root fragments of L. esculentum) or for $45 \mathrm{~min}$ (the other plant species) to the citrate-buffered mixture ( $\mathrm{pH} \mathrm{5.0;40}{ }^{\circ} \mathrm{C}$ ) containing $2.5 \%(\mathrm{w} / \mathrm{v})$ pectinase from Aspergillus niger (Sigma), $2.5 \%$ (w/v) cellulase Onozuka R-10 from Trichoderma viride (Sigma), and $2.5 \%$ (w/v) pectolyase Y-23 (MP Biomedicals). Next, root tips were rinsed twice in cold PBS $\left(4^{\circ} \mathrm{C}\right)$, squashed onto microscope slides (Super-Frost, Menzel-Gläser) in a drop of cold PBS, and placed on dry ice. After $10 \mathrm{~min}$, cover slips were removed and the slides were washed with distilled water, followed by PBS and then air-dried. Macerated cells were permeabilized with $0.5 \%$ (v/v) Triton X-100 for 15 min, preincubated in the blocking buffer $(5 \% \mathrm{w} / \mathrm{v}$ BSA, $0.3 \% \mathrm{v} / \mathrm{v}$ Triton $\mathrm{X}-100, \mathrm{PBS})$ and then incubated overnight $\left(4^{\circ} \mathrm{C}\right)$ with primary monoclonal anti- $\beta$-tubulin antibodies $(1: 350$, Sigma) dissolved in the antibody dilution buffer $(1 \% \mathrm{w} / \mathrm{v}$ BSA, $0.3 \% \mathrm{v} / \mathrm{v}$ Triton X-100, PBS). Then the slides were washed in PBS and incubated at $25{ }^{\circ} \mathrm{C}$ for 90 min with secondary TRITC-conjugated anti-mouse IgG (whole molecule; 1:250, Sigma) dissolved in the antibody dilution buffer $(1 \% \mathrm{w} / \mathrm{v}$ BSA, $0.3 \%$ v/v Triton X-100, PBS).

Next, the slides were incubated for $16 \mathrm{~h}\left(4{ }^{\circ} \mathrm{C}\right)$ with primary monoclonal anti-phospho-p44/44 MAPK antibodies (1:100, cell signaling) dissolved in the antibody dilution buffer (1\% w/v BSA, $0.3 \%$ v/v Triton X-100, PBS). Then, the slides were washed in PBS and incubated at $25{ }^{\circ} \mathrm{C}$ for $90 \mathrm{~min}$ with secondary FITC-conjugated antirabbit IgG (whole molecule; 1:350, Sigma) dissolved in the antibody dilution buffer ( $1 \% \mathrm{w} / \mathrm{v}$ BSA, $0.3 \% \mathrm{v} / \mathrm{v}$ Triton $\mathrm{X}-100, \mathrm{PBS})$. Nuclear DNA was stained with $5 \mu \mathrm{M}$ DAPI (Sigma) for $15 \mathrm{~min}$, and then the slides were washed in PBS. The specimens were mounted in ProLong ${ }^{\circledR}$ Gold Antifade Reagent (Invitrogen).

Cells were photographed using a wide field fluorescence microscope (Eclipse E600W, Nikon) equipped with a filter for FITC (EX 465-495, DM 505, BA 515-555), TRITC (EX 540/2, DM 565, BA 605/55) and DAPI (EX 340-380, DM 400, BA 435-485). Images were acquired with oil immersion $\times 100 /$ NA 1.3 . Impact of FR180204 on microtubule dynamics in L. esculentum was studied by means of Leica Laser Scanning Confocal Microscopy (LSCM) platform using laser line UV $405 \mathrm{~nm}$ and laser line supercontinuum visible $552 \mathrm{~nm}$. Images were acquired with oil immersion $\times 100 /$ NA 1.4 .

Mitotic indices and phase indices analyses

$1.5 \mathrm{~cm}$ long root apical fragments were fixed in Carnoy's mixture (ethanol/glacial acetic acid, 3/1, v/v) for $1 \mathrm{~h}$. Following fixation, the roots were rinsed three times in $96 \%$ ethanol, rehydrated (70-30\% ethanol, distilled water), hydrolysed in $4 \mathrm{M} \mathrm{HCl}$ (1.5 h for $V$. faba and $1 \mathrm{~h}$ for the other plant species) and stained with Schiff's reagent (pararosaniline). After $1 \mathrm{~h}$ of staining, the roots

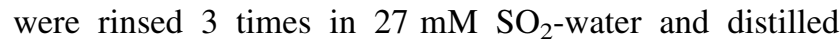
water. Root tips (1.5-2 mm long) were excised and squashed in a drop of $45 \%$ (v/v) acetic acid onto slides using the dry ice method. After removing cover slips, the slides were plunged into $70 \%$ ethanol, air-dried and mounted in Canada balsam.

Measurements and statistical analysis

Pearson's correlation coefficient (R) was estimated by means of Fiji Is Just ImageJ Software, co-localization threshold mode (Schindelin et al. 2012). RGB (red-greenblue) pictures were split for red and green channels before analyses. ROI (region of interest), selected on images of $\beta$ tubulin immunodetection, refers to mitotic microtubules.

Mean immunolabeling indices (including the values calculated for mitoses and for successive phases of 
mitoses) were evaluated based on the analyses of 4 roots (ca. 150 analyzed cells per root) for each plant species. Total labeling index expresses the ratio of TEY-immunopositive mitotic cells to all mitotic cells. The labeling index for each phase of mitosis indicates the ratio of TEY-immunopositive cells at a particular stage of mitosis to all cells at this stage of mitosis. To evaluate mean values of mitotic index and phase index, 5 roots (for $V$. faba and $P$. sativum) and 10 roots (for L. esculentum and L. luteus) per each plant species (ca. 1,500-2,500 cells per root) were analyzed in Feulgen-stained specimens. Statistical analysis was performed using STATISTICA 10 PL Software. Differences between groups were assessed by Student $t$ test. A $p$ value $\leq 0.05$ was considered statistically significant.

\section{Results}

\section{V. faba, P. sativum, L. luteus and L. esculentum display} differences in molecular masses of MAPKs

Western blot (WB) analyses of crude extracts derived from the root apical fragments were performed with the use of monoclonal antibodies detecting human p-44/42 kinases dually phosphorylated in their conservative TEY motif. These antibodies have been already applied successfully in A. thaliana (Beck et al. 2011; González Besteiro et al. 2011). Similar to previous data, apart from plant homologs of ERK1/2 kinases, a number of proteins matching alternative types of MAPKs were immunodetected. Although all studied plants, V. faba, P. sativum, L. luteus and $L$. esculentum, showed five characteristic groups of proteins, some differences in the band position and in the quantity of phosphorylated molecules were found between species. $V$. $f a b a$ and $P$. sativum displayed similar molecular masses of MAPKs while some differences in the extent of phosphorylation were revealed between these two species. However, among Fabaceae, a slightly different pattern of WB bands was found for L. luteus. Interestingly, unlike legumes, the molecular masses of immunodetected proteins extracted from L. esculentum were different (Fig. 1). The obtained results indicate that MAPK molecules display variable molecular masses in evolutionarily distinct plants, however, slight differences may also appear within the same family.

High level of MAPKs phosphorylation in the control plants prompted us to investigate whether cutting the root tip before homogenization induced kinase activation. Apical fragments of $V$. faba roots were excised on dry ice before homogenization both in the control plants and in those exposed to genotoxic stress (treated with $0.01 \% \mathrm{v} / \mathrm{v}$ MMS for $6 \mathrm{~h}$ ). The control plants displayed similar level of MAPKs phosphorylation irrespective to whether or not

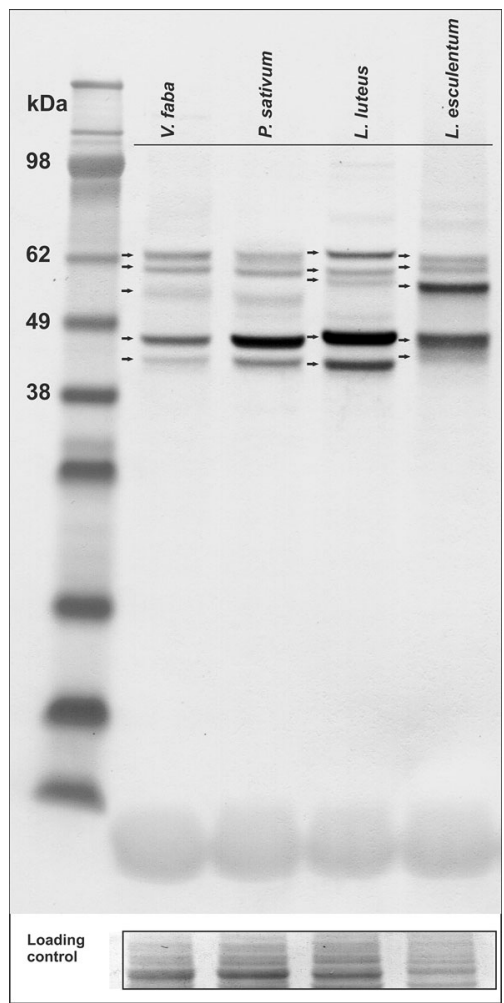

Fig. 1 Immumoblotting analysis of dually phosphorylated MAPKs at $\mathrm{Thr} / \mathrm{Tyr}$ in the whole-cell extracts. Loading control represents the level of proteins with molecular mass ranging from 80 to $98 \mathrm{kDa}$, detected with Ponceau S stain. Arrows point to bands of interest

they had been excised on dry ice before homogenization. Furthermore, increase in the phosphorylation of MAPKs was found after MMS treatment in both cases. Notably, the extract from non-stressed A. thaliana seedlings (loaded as a control) showed only two bands corresponding to MPK3 and MPK6 (Fig. S1).

Not all plants display co-localization of activated MAPKs to spindle microtubules in their root meristem cells

Immunocytochemical analyses of root meristem cells clearly demonstrated nuclear localization of dually phosphorylated MAPKs in all studied species (Figs. 2, 3, 4, 5). In contrast to other plants, $V$. faba displayed immunofluorescence signals organized in regularly shaped foci (Fig. 4).

The most evident co-localization of dually phosphorylated MAPKs and mitotic microtubules was found in $L$. esculentum (Fig. 2). In this case, immunolabeled mitotic cells reached $95 \%$ (Fig. 6a). In almost all metaphase cells (99\%), strong fluorescence signals appeared at kinetochore microtubules. From anaphase (labeling index $=96 \%$ ) to telophase (labeling index $=98 \%$ ) 

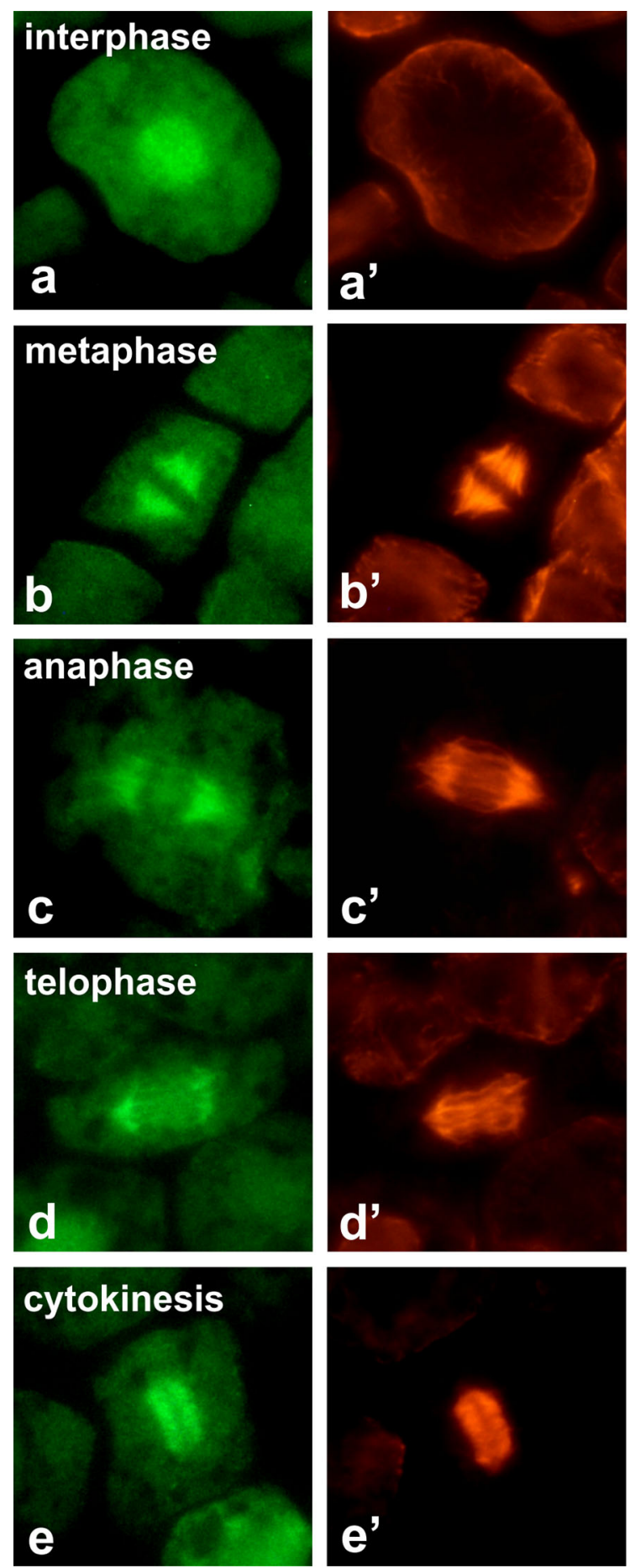

Fig. 2 Co-localization of dually phosphorylated MAPKs at Thr/Tyr and $\beta$-tubulin in interphase cells and during successive stages of mitosis in L. esculentum. a-d Immunodetection of dually phosphorylated MAPKs, a'-d' immunodetection of $\beta$-tubulin, a"-d" DAPI

immunofluorescence signals at kinetochore microtubules diminished successively due to microtubule shortening. During cytokinesis (labeling index $=94 \%$ ), immunofluorescence signals were found at a phragmoplast (Fig. 6b).
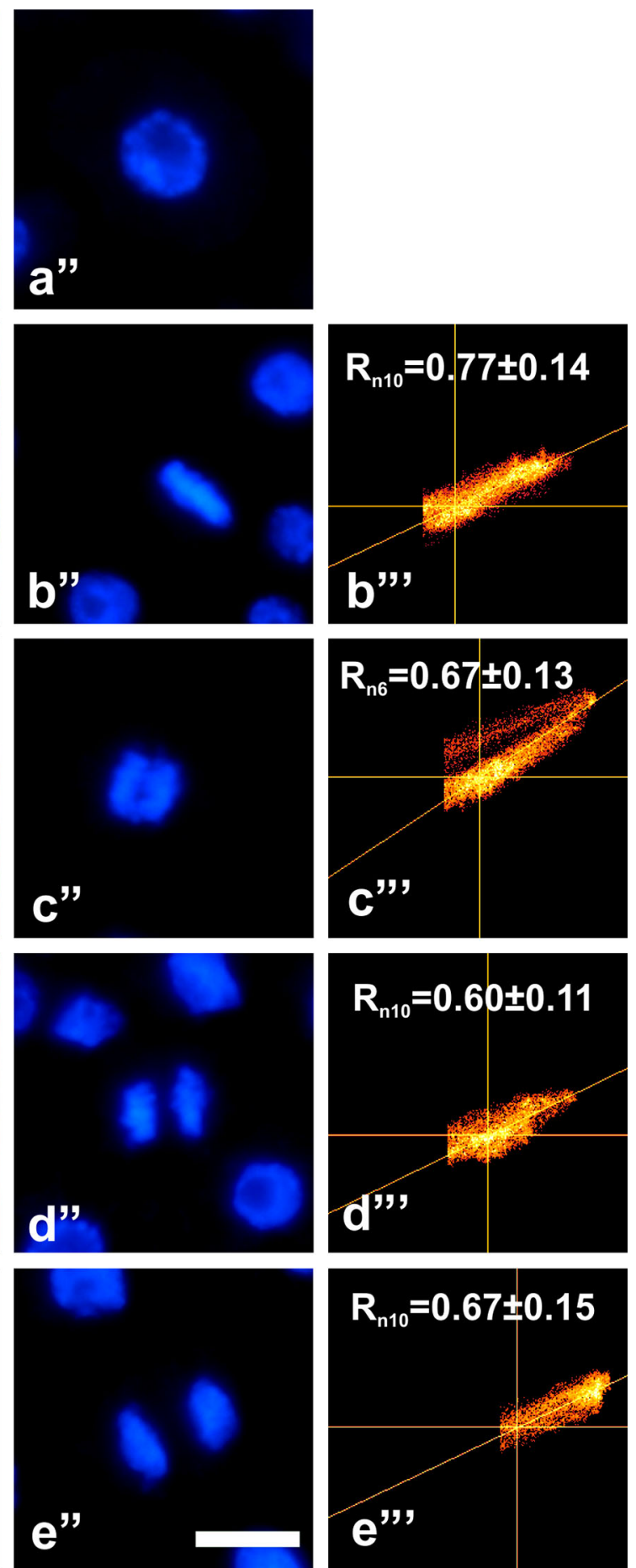

staining, b"',d'", scatter plots of representative images. $R$ depicts mean values of Pearson's correlation coefficient above a threshold, $n$ indicates number of analyzed mitotic figures. Bar $10 \mu \mathrm{m}$

Similar localization of dually phosphorylated MAPKs was found in P. sativum (Fig. 3); however, the percentage of immunolabeled mitotic cells declined to $42 \%$ (Fig. 6a). In this case, immunolabeled cells in metaphase reached $75 \%$, 

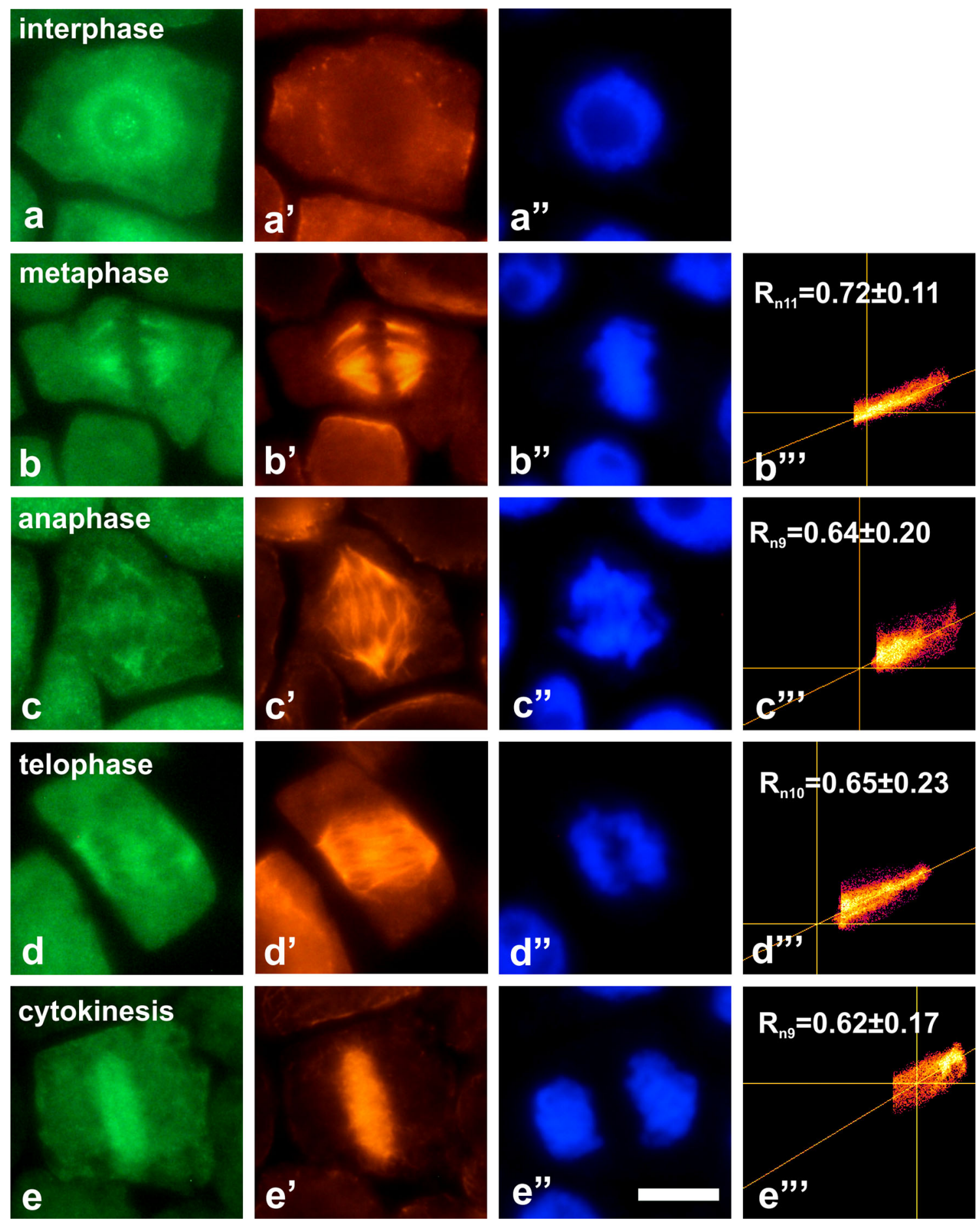

Fig. 3 Co-localization of dually phosphorylated MAPKs at Thr/Tyr and $\beta$-tubulin in interphase cells and during successive stages of mitosis in $P$. sativum. a-d Immunodetection of dually phosphorylated MAPKs, (a'-d' immunodetection of $\beta$-tubulin, $\mathbf{a}$ "-d" DAPI staining,

b" '-d", scatter plots of representative images. $R$ depicts mean values of Pearson's correlation coefficient above a threshold, $n$ indicates number of analyzed mitotic figures. Bar $10 \mu \mathrm{m}$

in anaphase $70 \%$, in telophase $42 \%$ and during cytokinesis only $26 \%$ (Fig. 6b). Similar value of the labeling index $(53 \%)$ was found for root meristem cells of $V$. faba (Fig. 6a); nevertheless, co-localization of activated

MAPKs to spindle microtubules seemed to be less unequivocal than in the former species (Fig. 4). Although the labeling index estimated for metaphase cells reached $75 \%$, it declined during successive stages of mitosis to 

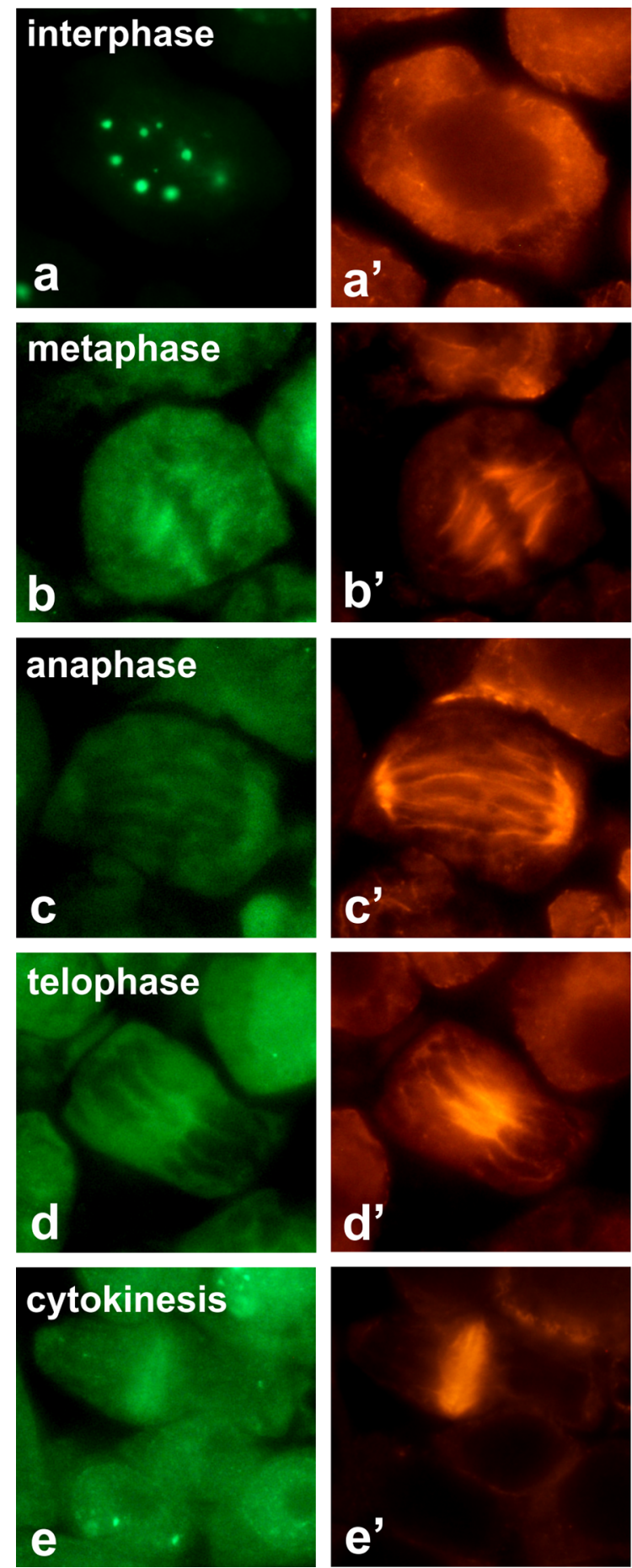

Fig. 4 Co-localization of dually phosphorylated MAPKs at Thr/Tyr and $\beta$-tubulin in interphase cells and during successive stages of mitosis in $V$. faba. a-d Immunodetection of dually phosphorylated MAPKs, a'-d' immunodetection of $\beta$-tubulin, a-d DAPI staining,

$26 \%$ in anaphase, $36 \%$ in telophase, and $3 \%$ in cytokinesis (Fig. 6b). Despite the fact that L. luteus showed no evident fluorescence signals at spindle microtubules and a phragmoplast (Fig. 5), some faint immunofluorescence
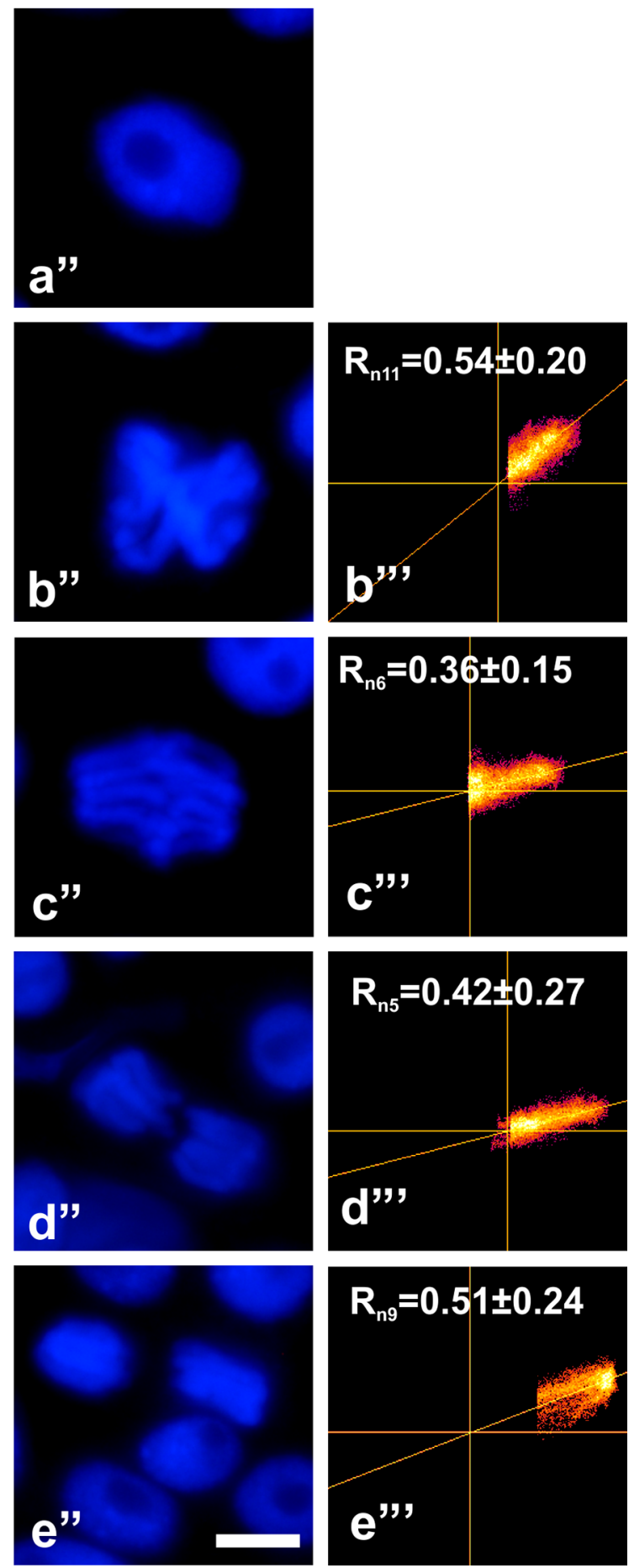

b" '-d", scatter plots of representative images. $R$ depicts mean values of Pearson's correlation coefficient above a threshold, $n$ indicates number of analyzed mitotic figures. Bar $10 \mu \mathrm{m}$

could still be seen in 5-6\% of metaphase and anaphase cells (Figs. 5, 6b). Notably, the frequency of phosphoTEY-positive mitotic cells was lower than $2 \%$ (Fig. 6a). Since phosphorylation of MAPKs appeared in the nuclei of 

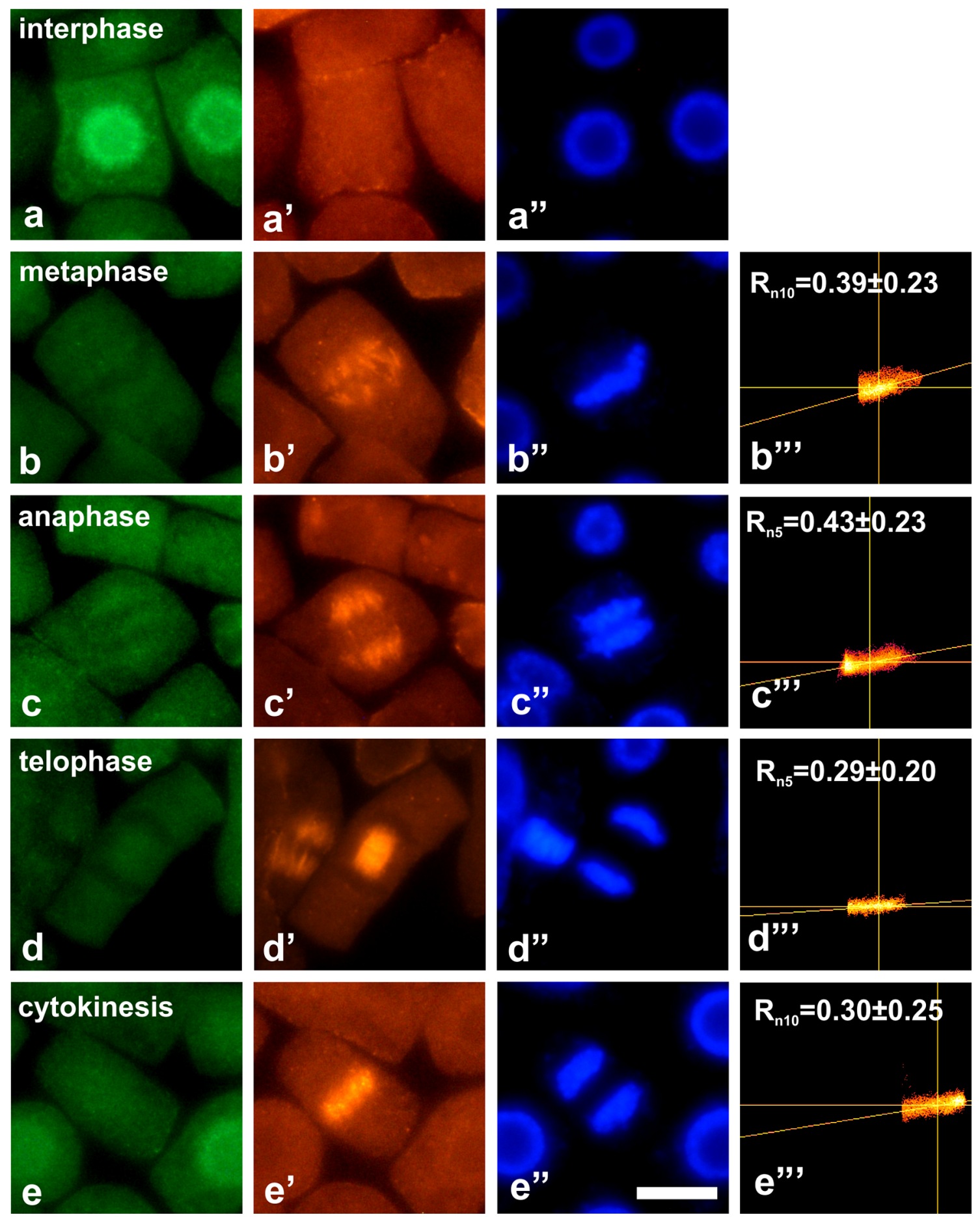

Fig. 5 Co-localization of dually phosphorylated MAPKs at Thr/Tyr and $\beta$-tubulin in interphase cells and during successive stages of mitosis in L. luteus. a-d Immunodetection of dually phosphorylated MAPKs, a'-d' immunodetection of $\beta$-tubulin, a"-d" DAPI staining,

L. luteus root meristem cells, lack of evident co-localization of activated MAPKs and spindle microtubules does not seem to be an artifact.

Mean values of Pearson's correlation coefficient $(R)$ indicate different degree of correlation between green

b" '-d", scatter plots of representative images. $R$ depicts mean values of Pearson's correlation coefficient above a threshold, $n$ indicates number of analyzed mitotic figures. Bar $10 \mu \mathrm{m}$

and red channels in various plant species. The highest $R$ values were obtained for L. esculentum (Fig. 2b', $-\mathrm{d}$,', and $P$. sativum (Fig. 3b",'-d,',). Weaker correlation was found for $V$. faba (Fig. 4b",'-d,', whereas the smallest $R$ values were obtained for L. luteus (Fig. 5b','-d','). 


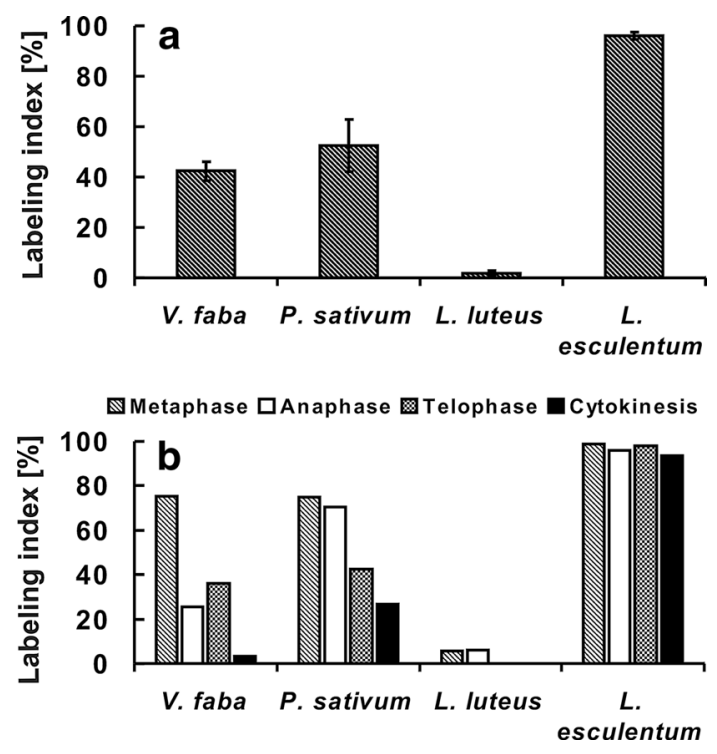

Fig. 6 Labeling indices (\%) estimated for root meristem cells stained with anti-phospho-p44/42 (Thr/Tyr) antibodies. a Total labeling indices, $\mathbf{b}$ labeling indices in the individual phases of mitosis

Single-labeled control (detection of dually phosphorylated ERK1/2) and secondary antibodies control (simultaneous labeling with anti-mouse and anti-rabbit secondary antibodies applied after anti- $\beta$-tubulin primary antibodies) were used to assess bleed-through and exclude crossreaction between secondary antibodies, respectively. Additional experiments indicate that dually phosphorylated MAPKs display localization similar to that of spindle microtubules (Fig. S2). Furthermore, secondary antibodies show no evident cross-reactivity, however, small nonspecific background fluorescence for FITC channel was detected (Fig. S3).

Responses to FR180204, an inhibitor of animal ERK1/2, differ among plant species

The obtained data prompted us to investigate whether inhibition of MAPKs triggers differential effects in various plant species. To study this, plants were incubated in $80 \mu \mathrm{M}$ FR180204, an inhibitor of animal ERK1/2, for either 6 or $24 \mathrm{~h}$. Short, 6-h treatment affected mitosis only in the root meristem cells of L. esculentum. The presented data show a statistically significant increase in the number of prometaphases and a decrease in the number of telophases (Fig. 7). Seedlings incubated in FR180204 for $24 \mathrm{~h}$ displayed an increase in the number of prometaphases only (Fig. 8).

Interestingly, despite the high percentage of immunolabeled metaphases and anaphases in the root meristem cells of $P$. sativum (Fig. 3b), the ERK1/2 inhibitor exerted no impact on the course of mitosis (Figs. 7, 8). The root meristems of $V$. faba and L. luteus displayed no changes in the percentage of cells at particular stages of mitosis upon 6-h incubation with FR180204 (Fig. 7); however, 24-h treatment brought about statistically significant increase in the percentage of anaphases or prometaphases, respectively (Fig. 8). Although, mitotic indices remained unchanged upon 6-h treatment with FR180204 (Fig. 9a), 24-h treatment brought about a statistically significant increase in the mitotic index in L. luteus (Fig. 9b).

Since, L. esculentum displayed the strongest response to FR180204, impact of an ERK1/2 inhibitor on the mitotic spindle was studied by means of LSCM. Upon 6-h treatment, some dividing cells demonstrated problems with formation of the mitotic spindle. Microtubules seemed to display ectopic accumulation and improper direction of their polymerization (Fig. 10).

\section{Discussion}

In this study, we applied commercially available antibodies against dually phosphorylated TEY motif in animal ERK1/ 2 kinases. WB analyses revealed five groups of proteins ranging from 40 to $62 \mathrm{kDa}$. Since kinases with TEY and TDY sequences displayed in $L$. esculentum different molecular masses, ranging from 42.72 to $45.51 \mathrm{kDa}$ and from 51.98 to $70.55 \mathrm{kDa}$, respectively (Kong et al. 2012), we speculate that the applied antibodies, due to possible cross-reactivity, immunodetected in the studied plants two types of MAPKs, containing either TEY or TDY sequences in their activation loops. Based on the data presented by Kong et al. (2012), it is possible to make some predictions and attribute the protein bands immunodetected in L. esculentum, respectively, to MAPK1/MAPK2, MAPK10, MAPK14, MAPK15 and MAPK16. Furthermore, one of the immunodetected bands $(\approx 43 \mathrm{kDa})$ in $P$. sativum could correspond to MPK2 (Ortiz-Masia et al. 2008). We demonstrated that MAPKs displayed different molecular masses in various plant species. The diversity in molecular masses was found not only between the plants representing distinct families but also within the same family, which seems to be an interesting aspect for further studies in the context of evolution and adaptation.

High level of MAPKs phosphorylation in the nonstressed plants, although not described previously, seems to be pertinent especially when we consider high expression of MAPKs in roots and carefully analyze the level of constitutive activity of MAPK proteins obtained during studies on environmental stress (Ortiz-Masia et al. 2008; Neupane et al. 2013a, b). Notably, our supplementary data indicated that cutting off apical root fragments before protein isolation did not induce detectable MAPKs-related stress. It is very probable that the low level of MAPKs 
Fig. 7 Percentage of cells in successive phases of mitosis (phase index) evaluated for plants incubated in water (control) or $80 \mu \mathrm{M}$ FR180204 for 6 h. Error bars depict standard deviation. Asterisks indicate statistical significance (control versus FR180204, $p$ value $\leq 0.05$ )

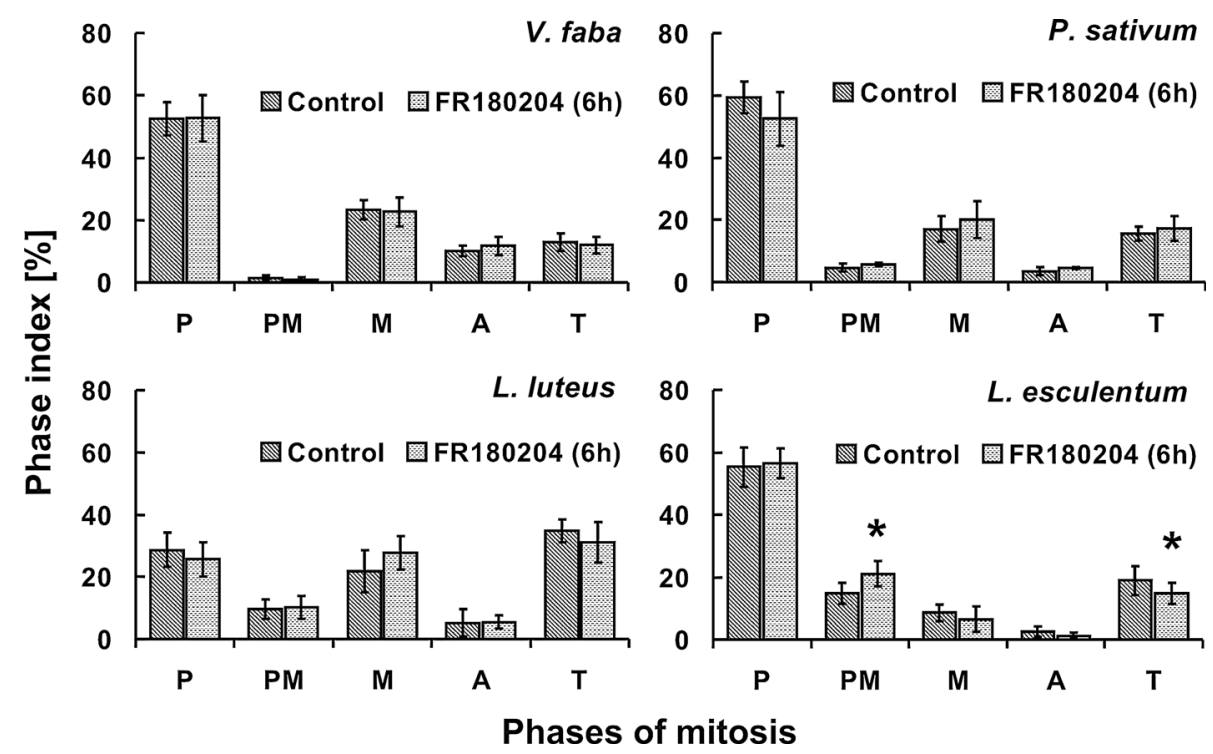

Fig. 8 Percentage of cells in successive phases of mitosis (phase index) evaluated for plants incubated in water (control) or $80 \mu \mathrm{M}$ FR 180204 for 24 h. Error bars depict standard deviation. Asterisks indicate statistical significance (control versus FR180204, $p$ value $\leq 0.05)$. $P$ prophase, $P M$ prometaphase, $M$ metaphase, $A$ anaphase, $T$ telophase

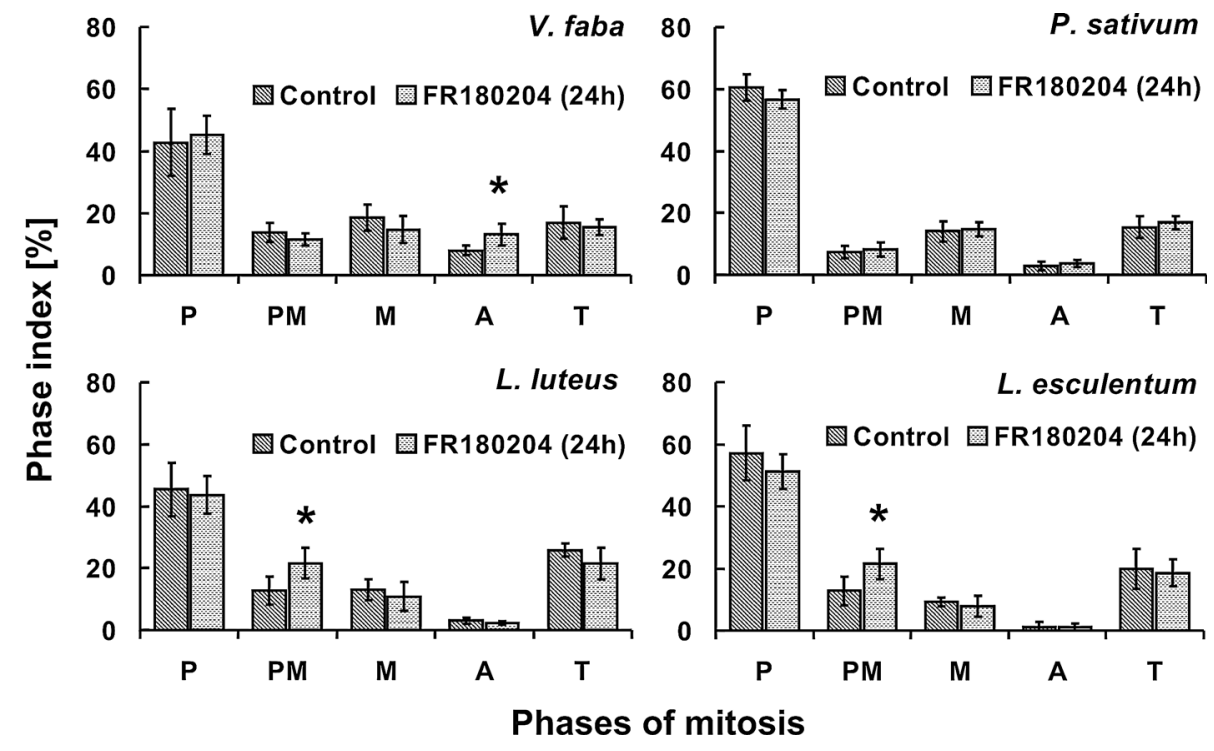

phosphorylation in the control plants presented by others in environmental stress studies resulted from the short time of signal detection during Western blot analyses. Strong signal appearing rapidly in plants under stress conditions might have urged early termination of signal detection, thus preventing detection of phosphorylated MAPKs in the control plants.

Immunolocalization studies seem to be consistent with earlier data showing a prominent role of MAPKs during interphase and cell division (Bögre et al. 1999; Liu et al. 2004; Beck et al. 2010, 2011; Komis et al. 2011; Šamajová et al. 2013). By revealing stress-independent nuclear localization of activated MAPKs, our data strongly support the idea that these kinases control cell growth, differentiation and development not only influencing cytoskeleton dynamics but also regulating gene expression. However, the function of MAPK signaling pathways is still poorly understood in plants. Surprisingly, saltinduced relocation of nuclear pools of both SIMKK (stress-induced MAPKK) and SIMK (stress-induced MAPK) to cytoplasmic compartments was found recently (Ovečka et al. 2014).

The obtained data indicating evident co-localization of dually phosphorylated MAPKs and microtubules in metaphase, anaphase, telophase and during cytokinesis in $L$. esculentum and less pronounced in $P$. sativum and $V$. faba support previous studies pointing to essential role of MAPK signaling pathway in regulation of mitotic microtubule dynamics (Smékalová et al. 2014; Müller et al. 2010; Beck et al. 2010; Kosetsu et al. 2010). 


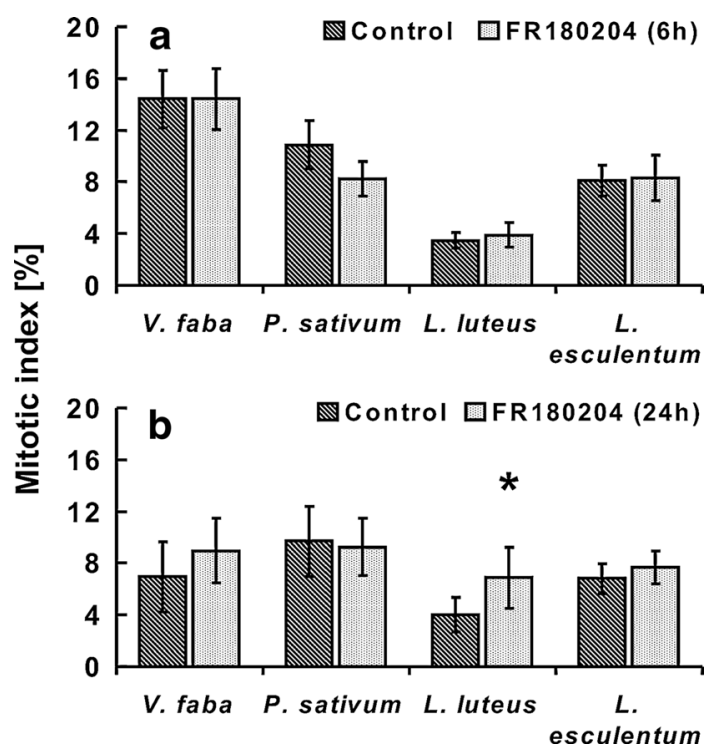

Fig. 9 Percentage of mitotic cells (mitotic index) evaluated for different plant species. a Seedlings incubated in water (control) or $80 \mu \mathrm{M}$ FR180204 for $6 \mathrm{~h}$. b Seedlings incubated in water (control) or $80 \mu \mathrm{M}$ FR 180204 for 24 h. Error bars represent standard deviation. Asterisks indicate statistical significance (control versus FR180204, $p$ value $\leq 0.05)$. $P$ prophase, $P M$ prometaphase, $M$ metaphase, $A$ anaphase, $T$ telophase

Bögre et al. (1999) showed that a homolog of $V$. faba MMK3 kinase (one of Medicago sativa MAPK) was dispersed in metaphase cells, localized between chromosomes in early anaphase and confined to the phragmoplast during cytokinesis. This seems to contradict our results; however, the discrepancy may have appeared since we have immunodetected the whole spectrum of activated MAPKs whereas other studies were restricted to a particular type of kinase with its function possibly limited to a specific phase of mitosis (e.g. cytokinesis only). Moreover, it is probable that the immunofluorescence detected by Bögre et al. (1999) in metaphase cells of $V$. faba reflected both phosphorylated kinases localized to microtubules and inactive kinases dispersed in the cytoplasm.

Nevertheless, our results showed that the numbers of mitotic cells displaying co-localization of dually phosphorylated MAPKs to mitotic microtubules (if only detectable), differed depending on plant species. This, together with the lack of phospho-MAPKs immunofluorescence in mitotic microtubules of $L$. luteus, may indicate that in some plants the functioning of mitotic spindle is governed by other factors, e.g. CDK (cyclin-dependent kinase), which have already been found to cooperate with MAPKs in the regulation of microtubule dynamics (Smertenko et al. 2006). It is very probable that the mitotic microtubules in L. luteus are regulated mostly by CDKs.

Limited participation of MAPKs in the regulation of mitotic microtubules in some species may also be

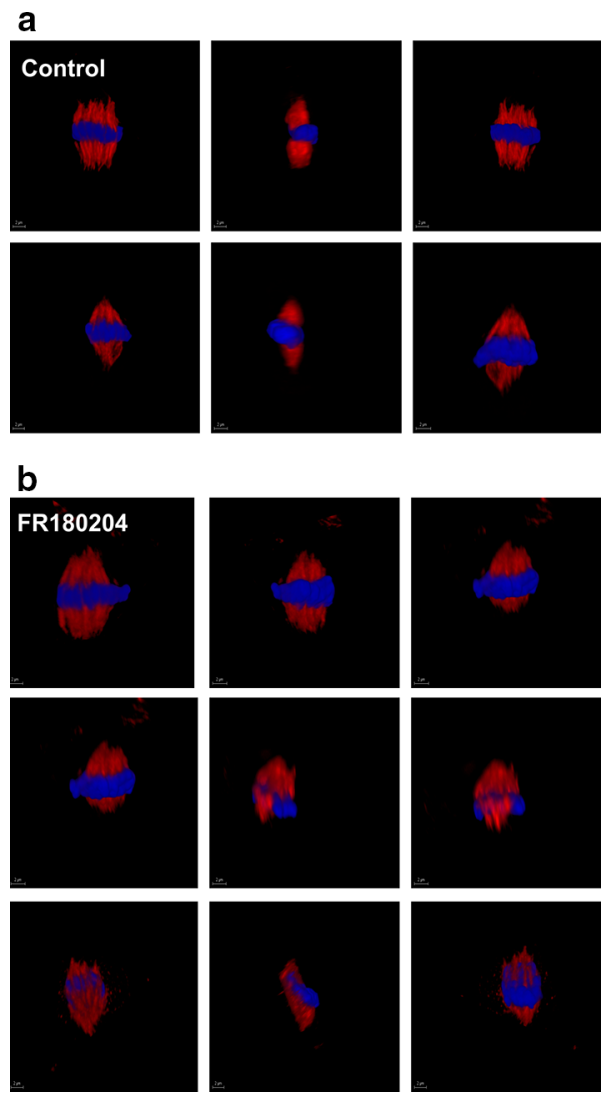

Fig. 10 3-D images showing mitotic microtubules (red channel) in root meristem cells of $L$. esculentum during metaphase. a Control plants, b plants treated with $80 \mu \mathrm{M}$ FR180204. Blue channel represents DAPI staining. Across different views of the same mitotic figure, down different mitotic figures (color figure online)

supported by differential response to FR180204, an inhibitor of animal ERK1/2. We assume that only a short, 6-h treatment reflects the direct impact of the inhibitor on microtubule dynamics. Thus, we hypothesize that in $V$. faba and L. luteus increases in the number of anaphases and prometaphases, respectively, upon prolonged 24-h treatment result from the effect of MAPKs inactivation on other proteins that control a cell cycle. Notably, it was previously found that inhibition of the MAPK signaling pathway in liver cancer cells triggered a decrease in CDK1 expression (Bessard et al. 2008). It was shown in plants that particular phases of mitosis were prolonged in cells with non-functional MAPK signaling pathway (Beck et al. 2011). Thus, similar numbers of prometaphases in $L$. esculentum obtained during 6- and 24-h treatments may suggest that the applied concentration of FR180204 extended the duration of prometaphases (due to microtubule disorders) rather than triggered a permanent block at this stage of mitosis. In turn, the increase in the number of telophases in seedlings of $L$. esculentum incubated with FR180204 for $24 \mathrm{~h}$ (compared to the plants treated for $6 \mathrm{~h}$ ) may result 
from prolonged duration of telophases due to deregulation of cellular mechanisms controlling a cell cycle. Unlike severe mitotic microtubule disorders in MAPKs signaling mutants, moderate disturbances in the structure of mitotic apparatus upon FR180204 treatment were found in L. esculentum. It seems to support the transient effect of this inhibitor; however, at the same time it is probable that the applied concentration of FR180204 did not significantly affect plant MAPKs. Nevertheless, disturbances of the direction of microtubule polymerization during mitosis observed in our studies seem to be consistent with data presenting misaligned cell division planes in yda (one of MAPKKK) mutants (Smékalová et al. 2014).

Since the largest percentage of immunolabeled mitotic cells and clear response to 6-h treatment with FR180204 was found only in L. esculentum, it may implicate that in this species, contrary to the other studied plants, microtubule dynamics is mostly regulated by MAPKs. Although FR180204 seemed to have no impact on the function of mitotic spindle in $P$. sativum and $V$. faba, due to visible colocalization of MAPKs and mitotic microtubules, at least in about $70 \%$ of metaphase cells, we hypothesize that these kinases may play a different role during cell division, other than controlling microtubule bundling. Furthermore, variable numbers of phospho-TXY-MAPKs immunopositive cells at successive stages of mitosis observed in P. sativum and $V$. faba seem to indicate that the time of MAPKs action during cell division might depend on the predominance of either anaphase $\mathrm{A}$ or B; both types are found in plants (Hayashi et al. 2007). Notably, contrary to the data presented by Müller et al. (2010), none of the plants examined in our study demonstrated an activated MAPK localization to preprophase band.

\section{Conclusions}

The presented data indicate that the molecular masses of MAPKs differ not only in evolutionarily distinct plants but also between species belonging to the same family. Moreover, it appears that the functioning of a mitotic spindle may be independent of the activity of MAPKs in some plants. Thus, a hypothesis could be put forward that some plants phosphorylate MAP65, and thereby regulate the dynamic of mitotic microtubules independently of the MAPK signaling pathway (e.g. involving alternative kinases, such as CDKs). Participation of CDKs in hyperphosphorylation of MAP65 was previously shown (Smertenko et al. 2006). This idea might be also supported by the differential response to FR180204 among various plant species. A more detailed analysis needs to be performed to investigate the processes controlled by the MAPK signaling pathway and to shed new light on plant molecular evolution that may occur at the level of entire signaling pathways.

Author contribution statement KW conceived and designed research and analyzed data. KW, AŻ, JB and KM conducted experiments. $\mathrm{KW}$ and JM wrote the manuscript. All the authors read and approved the manuscript.

Conflict of interest The authors declare that they have no conflict of interest.

Open Access This article is distributed under the terms of the Creative Commons Attribution License which permits any use, distribution, and reproduction in any medium, provided the original author(s) and the source are credited.

\section{References}

Beck M, Komis G, Müller J, Menzel D, Samaj J (2010) Arabidopsis homologs of nucleus- and phragmoplast-localized kinase 2 and 3 and mitogen-activated protein kinase 4 are essential for microtubule organization. Plant Cell 22:755-771

Beck M, Komis G, Ziemann A, Menzel D, Samaj J (2011) Mitogenactivated protein kinase 4 is involved in the regulation of mitotic and cytokinetic microtubule transitions in Arabidopsis thaliana. New Phytol 189:1069-1083

Bessard A, Frémin C, Ezan F, Fautrel A, Gailhouste L, Baffet G (2008) RNAi-mediated ERK2 knockdown inhibits growth of tumor cells in vitro and in vivo. Oncogene 27:5315-5325

Bögre L, Calderini O, Binarova P, Mattauch M, Till S, Kiegerl S, Jonak C, Pollaschek C, Barker P, Huskisson NS, Hirt H, Heberle-Bors E (1999) A MAP kinase is activated late in plant mitosis and becomes localized to the plane of cell division. Plant Cell 11:101-113

Cargnello M, Roux PP (2011) Activation and function of the MAPKs and their substrates, the MAPK-activated protein kinases. Microbiol Mol Biol Rev 75:50-83

Fernandez-Pascual M, Lucas MM, de Felipe MR, Boscá L, Hirt H, Golvano MP (2006) Involvement of mitogen-activated protein kinases in the symbiosis Bradyrhizobium-Lupinus. J Exp Bot 57:2735-2742

González Besteiro MA, Bartels S, Albert A, Ulm R (2011) Arabidopsis MAP kinase phosphatase 1 and its target MAP kinases 3 and 6 antagonistically determine UV-B stress tolerance, independent of the UVR8 photoreceptor pathway. Plant J 68:727-737

Hayashi T, Sano T, Kutsuna N, Kumagai-Sano F, Hasezawa S (2007) Contribution of anaphase B to chromosome separation in higher plant cells estimated by image processing. Plant Cell Physiol 48:1509-1513

Horne MM, Guadagno TM (2003) A requirement for MAP kinase in the assembly and maintenance of the mitotic spindle. J Cell Biol 161:1021-1028

Komis G, Illés P, Beck M, Šamaj J (2011) Microtubules and mitogenactivated protein kinase signalling. Curr Opin Plant Biol 14:650-657

Kong F, Wang J, Cheng L, Liu S, Wu J, Peng Z, Lu G (2012) Genome-wide analysis of the mitogen-activated protein kinase gene family in Solanum lycopersicum. Gene 499:108-120

Kosetsu K, Matsunaga S, Nakagami H, Colcombet J, Sasabe M, Soyano T, Takahashi Y, Hirt H, Machida Y (2010) The MAP 
kinase MPK4 is required for cytokinesis in Arabidopsis thaliana. Plant Cell 22:3778-3790

Krysan PJ, Jester PJ, Gottwald JR, Sussman MR (2002) An Arabidopsis mitogen-activated protein kinase kinase kinase gene family encodes essential positive regulators of cytokinesis. Plant Cell 14:1109-1120

Ligterink W, Kroj T, Nieden U, Hirt H, Scheel D (1997) Receptormediated activation of a MAP kinase in pathogen defense of plants. Science 276:2054-2057

Liu X, Yan S, Zhou T, Terada Y, Erikson RL (2004) The MAP kinase pathway is required for entry into mitosis and cell survival. Oncogene 23:763-776

MAPK Group (2002) Mitogen-activated protein kinase cascades in plants: a new nomenclature. Trends Plant Sci 7:301-308

Mishra NS, Tuteja R, Tuteja N (2006) Signaling through MAP kinase networks in plants. Arch Biochem Biophys 452:55-68

Müller J, Beck M, Mettbach U, Komis G, Hause G, Menzel D, Samaj J (2010) Arabidopsis MPK6 is involved in cell division plane control during early root development, and localizes to the preprophase band, phragmoplast, trans-Golgi network and plasma membrane. Plant J 61:234-248

Nakagami H, Pitzschke A, Hirt H (2005) Emerging MAP kinase pathways in plant stress signalling. Trends Plant Sci 10:339-346

Neupane A, Nepal MP, Benson BV, Macarthur KJ, Piya S (2013a) Evolutionary history of mitogen-activated protein kinase (MAPK) genes in Lotus, Medicago, and Phaseolus. Plant Signal Behav. 8(11):e27189. doi:10.4161/psb.27189

Neupane A, Nepal MP, Piya S, Subramanian S, Rohila JS, Reese RN, Benson BV (2013b) Identification, nomenclature, and evolutionary relationships of mitogen-activated protein kinase (MAPK) genes in soybean. Evol Bioinform 9:363-386

Ohori M, Takeuchi M, Maruki R, Nakajima H, Miyake H (2007) FR180204, a novel and selective inhibitor of extracellular signalregulated kinase, ameliorates collagen-induced arthritis in mice. Naunyn Schmiedebergs Arch Pharmacol 374:311-316

Ortiz-Masia D, Perez-Amador MA, Carbonell P, Aniento F, Carbonell J, Marcote MJ (2008) Characterization of PsMPK2, the first C1 subgroup MAP kinase from pea (Pisum sativum L.). Planta 227:1333-1342

Ovečka M, Takáč T, Komis G, Vadovič P, Bekešová S, Doskočilová A, Šamajová V, Luptovčiak I, Samajová O, Schweighofer A, Meskiene I, Jonak C, Křenek P, Lichtscheidl I, Škultéty L, Hirt H, Šamaj J (2014) Salt-induced subcellular kinase relocation and seedling susceptibility caused by overexpression of Medicago SIMKK in Arabidopsis. J Exp Bot 65:2335-2350

Perrett RM, Fowkes RC, Caunt CJ, Tsaneva-Atanasova K, Bowsher CG, McArdle CA (2013) Signaling to extracellular signalregulated kinase from ErbB1 kinase and protein kinase C: feedback, heterogeneity, and gating. J Biol Chem 288:21001-21014
Pitzschke A, Hirt H (2006) Mitogen-activated protein kinases and reactive oxygen species signaling in plants. Plant Physiol 141:351-356

Qian X, Mills E, Torgov M, LaRochelle WJ, Jeffers M (2008) Pharmacologically enhanced expression of GPNMB increases the sensitivity of melanoma cells to the CR011-vcMMAE antibody-drug conjugate. Mol Oncol 2:81-93

Šamajová O, Komis G, Šamaj J (2013) Emerging topics in the cell biology of mitogen-activated protein kinases. Trends Plant Sci 18:140-148

Sasabe M, Soyano T, Takahashi Y, Sonobe S, Igarashi H, Itoh TJ, Hidaka M, Machida Y (2006) Phosphorylation of NtMAP65-1 by a MAP kinase down-regulates its activity of microtubule bundling and stimulates progression of cytokinesis of tobacco cells. Genes Dev 20:1004-1014

Schindelin J, Arganda-Carreras I, Frise E, Kaynig V, Longair M, Pietzsch T, Preibisch S, Rueden C, Saalfeld S, Schmid B, Tinevez JY, White DJ, Hartenstein V, Eliceiri K, Tomancak P, Cardona A (2012) Fiji: an open-source platform for biologicalimage analysis. Nat Methods 9:676-682

Sinha AK, Jaggi M, Raghuram B, Tuteja N (2011) Mitogen-activated protein kinase signaling in plants under abiotic stress. Plant Signal Behav 6:196-203

Smékalová V, Luptovčiak I, Komis G, Šamajová O, Ovečka M, Doskočilová A, Takáč T, Vadovič P, Novák O, Pechan T, Ziemann A, Košútová P, Šamaj J (2014) Involvement of YODA and mitogen activated protein kinase 6 in Arabidopsis postembryogenic root development through auxin up-regulation and cell division plane orientation. New Phytol 203:1175-1193

Smertenko AP, Chang HY, Sonobe S, Fenyk SI, Weingartner M, Bögre L, Hussey PJ (2006) Control of the AtMAP65-1 interaction with microtubules through the cell cycle. J Cell Sci 119:3227-3237

Taj G, Agarwal P, Grant M, Kumar A (2010) MAPK machinery in plants: recognition and response to different stresses through multiple signal transduction pathways. Plant Signal Behav 5:1370-1378

Tena G, Asai T, Chiu WL, Sheen J (2001) Plant mitogen-activated protein kinase signaling cascades. Curr Opin Plant Biol 4:392-400

Ulm R (2003) Molecular genetics of genotoxic stress signalling in plants. Topics Curr Genet 4:217-240

Ulm R, Revenkova E, Di Sansebastiano GP, Bechtold N, Paszkowski J (2001) Mitogen-activated protein kinase phosphatase is required for genotoxic stress relief in Arabidopsis. Genes Dev 15:699-709

Wrzaczek M, Hirt H (2001) Plant MAP kinase pathways: how many and what for? Biol Cell 93:81-87 